\title{
Introducing Complex Situations in Primary Education:Their Impact on Student's Results in Terms of Equity
}

\author{
Alphonse Sebaganwa ${ }^{1, *}$ \\ ${ }^{1}$ Kigali Institute of Education, Rwanda \\ *Correspondence: Kigali Institute of Education, Rwanda. Tel: 250-785-137-690 E-mail: \\ sebaganwa_al@yahoo.fr
}

Received: May 17, 2015 Accepted: July 28, 2015 Published: September 30, 2015

doi:10.5296/ije.v7i4.8587 URL: http://dx.doi.org/10.5296/ije.v7i4.8587

\begin{abstract}
This paper examined the equity of using complex situations in teaching Science and Elementary Technology in 20 primary schools, 38 classes (only fourth years), located in Huye district in Rwanda. The sample was divided into four groups: 9 classes practiced the "teaching situations", 9 dealt with "integration situations", 9 mixed "teaching and integration situations" and 11 classes made a "reference group" that did not use any of those approaches.

One pre-test and three post-tests have been done by learners from those classes during the 2012 school year. Every test had a "resource" test and a "situation" test with a similar level of difficulties. The analysis indicated progressive increase of marks, especially, for the classes which practiced the "integration situations". The findings showed a priority of starting with the "integration situations" for the development of the learner's autonomy and of a cognitive development.
\end{abstract}

Keywords: complex situations, equity, teaching science, education, Rwanda 


\section{Introduction}

This paper explores the use of the complex situations in teaching Science and Elementary Technology (SET) in 20 primary schools (Huye District; Rwanda) and its impact on students' results in terms of equity.

This research is focused on the question of how to introduce complex situations in teaching and learning SET aiming to maximise equity. Indeed, some scholars De Ketele and Postic (1988), Roegiers (2010) recognize two different ways complex situations may be introduced at school. These authors understand complex situations as follows:

- "teaching situations" are situations of discovery and/or research. They are often conducted in small groups to construct learning, knowledge and know-how. The quoted authors describe such situations as a process largely inspired by social constructivism.

- "integration situations" are suggested to be complex and done at the end of a specific learning period (usually after 5 or 6 weeks). In addition each student is expected to utilize his / her prior acquisitions. The cited authors define integration situations as product that match with the profile of expected output.

This study attempts to address the following main questions:

-How and to what extent the introduction of teaching situations have an impact on student's results in learning SET in terms of equity?

-How and to what extent the introduction of integration situations influence student's results in learning SET in terms of equity?

-How and to what extent introducing the two approaches simultaneously, impact on student's results in terms of equity?

\section{Some elements of literature}

Equity in education is a major concern for most analysts of education systems. The OECD (2012), equity refers to the degree to which individuals can take advantage of education and training, in terms of opportunities, access, treatment and outcomes. A system is equitable if the results of the education and training are independent of socio-economic background and other factors that lead to educational disadvantage and that treatment reflects the specific needs of individuals in learning.

In the same sense, Gerard (2001), De Ketele (1996) and Meuret (2006) suggest that the concept of inequity is related to social justice: an educational system is more equitable if it reduces disparities between the strongest and weakest, between advantaged and disadvantaged groups.

According to McMahon (quoted by Psacharopoulos \& Woodhall, 1988, p 263), three types of equity can be identified:

- Horizontal equity, to which also gives the sense of equal treatment to equal individuals; 
- Vertical equity, which refers to unequal treatment of unequal individuals (which of course raises the question of how it should form a judgment on equality and inequality);

- Finally intergenerational inequality, which lies between the two types of equity and simply attaches to ensuring that existing inequities within a generation may not be transmitted to the next generation.

When faced with the possible interpretations of equity, Sall and De Ketele (1997) suggest that the evaluation of this takes into account five types of equity:

- The socio-economic equity of access, the indicators bind enrollment in a system with independent variables such as gender, socioeconomic status, ethnicity, previous studies ...;

- Pedagogical equity comfort considers indicators such as the level of teacher training, the coaching, the quantity and quality of teaching tools, rate ...;

- Equity of educational production leads to the question whether - the access and skills levels are equal at starting point -school programs should maintain the levelof educational output equivalency (this questioning is strongly related to what we call the balance of an education system);

- Educational equity, that Bressoux (1993) defines as reducing the gap between the strong and the weak in terms of academic performance at the beginning and the end of the educational activity;

- External equity or equity of accomplishment is concerned with equal opportunities to develop professionally at the end of training, for different groups in society, at equal level of training, or equal time of training.

In fact, inequity in this research is educational because its main purpose is to see how different pedagogical approaches reduce the gaps between the "strong" students and the 'weak' students in terms of improved scores obtained in the pre-tests and post-tests done by learners.

\subsection{Equity and efficacy in the educational systems}

The purpose of this is to gather evidence that could answer the question of whether some education systems are more efficient and / or more equitable than others, and know which one we must take in case of competition (Meuret, 1997). The author proposes a response from Rawls's theory: in education, equity is better than efficiency.

Theory of Justice by John Rawls gives priority to political freedoms on equal opportunities and responds to competition between equity and efficiency by the "principle of difference" between two similar states in terms of political freedoms and the equal opportunities, preference should be one in which the most disadvantaged have the highest expectations of "primary social goods" (wealth, power, self-respect) he is likely to have. For Rawls (cited by Meuret), the original "natural" inequalities are no more justified than the inequalities of social background, but they fall precisely because they are natural, some other type of regulation.

In short, for Rawls, a just system is a system where there is equal opportunity to achieve 
academic success and where equal qualifications, the chances of access to positions of responsibility are equal. Then, again for Rawls, between two identical education systems in terms of equality of opportunity, if we give priority to the social bases of self-respect, the fairest system is the one where interpersonal inequality will be minimal, while that if we give priority to wealth, most just may be the most effective, even if it requires to pay more attention to the most talented, but only if this greater internal efficiency results in improving a lot the most disadvantaged.

But can't we ask ourselves whether, in both cases, the privileging regardless of their social impact, effectiveness of education on fairness, the average score of students or that of academic elite on equal educational opportunity on the lower level or the gap between the weakest and strongest, is consistent with the theory of Rawls's justice?

Beyond setting competition efficiency and equity in education, De Ketele and Sall (1997) argue that it is futile to try to resist the logic of fairness to the logic of efficiency, at least if we think, not in terms of effects compartmentalized and short term, but in a systemic perspective and long term. Taking into account the time dimension, efficiency can not reach certain thresholds, if no action is taken where the most progress are possible; conversely, equity involves the development of competencies, based on their differential potential.

These authors also point out that different types or terms of effectiveness, efficiency and equity are always fulfilled simultaneously and maintain very complex interactions. It should therefore not study these concepts in isolation or simply overall indicator means that mask the reality of differentiation, or be satisfied of the only cross-sectional studies planning dynamic evolutionary process.

The same authors found that it is important to conduct longitudinal studies, through pathways and loss of specimens of the same cohort of initially reveal the true efficiency indicators to better understand the evolution of disparities if one takes the trouble to take the required information on the characteristics of individuals and groups in relation to the resources mobilized in time.

Also, it is important to conduct in-depth case studies to better understand the complex dynamics that is played between the phenomena associated with these three concepts of effectiveness, efficiency and equity, because ultimately it is always about groups differentiated unique people, in specific contexts in space and in time.

Particularly concerning the equity of education systems, Demeuse and Baye (2007) define it as the degree to which individuals can take advantage of education and training, in terms of opportunity, access, treatment and outcomes. According to these authors, this definition merge, without specifying different designs based on different requirements: equal opportunities on the one hand, effective equality of access, treatment or results on the other.

If the first concept refers to the idea of an equal potential (have virtually the same chance of getting a degree or other educational property), three other concern effective equalities have access to the same educational service (the eg higher education) receive equal treatment (and local teachers of equal quality), equality of outcome (eg, master basic skills). 
In the same vein, the European Commission (2007) states that a system is defined as just on one hand, if the results of the education and training are independent of socio-economic background and other factors leading to educational disadvantage and, on the other hand, if the treatment reflects the specific needs of individuals in learning.

Similarly, De Ketele and Sall (1995) attempt to study the relationship between efficiency and equity. According to them, the concept of equity can be better understood when it is considering:

- In light of the demand and supply of education,

- Throughout the educational process,

- At the end of the studies,

- And after their studies, that is to say in the social and professional lives.

For these authors, each of these steps is a specific kind of fairness.

They distinguish socioeconomic equity of access defined as equity towards school or satisfaction of the demand for education functions of individuals and different groups of society. This is a socio-economic equity because the socio-cultural environment and socio-economic conditions have a strong influence on education.

Socioeconomic equity access refers to the actual distribution of learners in a ring or in a training program. Enrollment status occupies dependent variable. Assessing the fairness towards school considers factors such as the nature and quality of teaching or existing training programs. In this sense, the level of equity towards school is based on the distribution of enrollment in training (at a level of education in a subsystem or an entire system). For the assessment of equity access, learners are identified by their main characteristics:

- Gender and age,

- The geographical origin and place of residence,

- Ethnicity and religion

- The level of education and occupation of parents,

- The allocation of scholarships and study grants,

- School history, etc.

These authors state that the socio-economic equity of access is different from the socio-economic equity in educational comfort because the first proved to be the most general analysis of the equity level. It reflects the level of fulfilling the democratic aspirations (or social expectations),

While the fairness of comfort (or equity in education) focuses on the distribution of study quality. Indeed, equity of educational comfort should be interested in analyzing the distribution of teaching positions in relation to the quality of education on the one hand, and social 
background and socioeconomic learners, on the other hand. In this sense, the question is whether disadvantaged groups have access to the same educational and comfort at the same quality of education as the favored groups.

The analysis here takes into account regional differences that may exist in a country. It assumes that all educational institutions do not have the same status and the same rating. The pedagogical comfort offered to students attending the same educational levels could vary by region, on one hand, and the status and rating of schools, on the other.

The status and rating of schools depend on factors such as:

- The geographical distribution of schools, which could result in differences in class size, resulting in differences in the student / teacher ratio,

- The geographical distribution of teachers given teacher training received,

- The geographical distribution of teachers according to their 'professionalism' and seniority,

- The quality of teaching materials and school documentation by school and region.

While the socio-economic equity in educational comfort is interested in the distribution of education depending on the quality of education, it is also important to measure the result of the efforts, within the education system, to improve the performance of learners (strong or weak) in training.

Another type of equity is educational. Bressoux (1993) cited by Sall (1996) shows that equity can be evaluated according to the results obtained by different groups of learners. It highlights a type of equity that is to reduce the gap between students deemed strong and weak students without lowering the level of strong ones. This is equity on learning throughout the school, equity could be identified as educational equity.

This would be primarily based software resources (RESlog), namely the implementation of teaching methods to improve student achievement, especially for special programs to support the weak, and the quality of human resources (teachers and administrative staff or managers) responsible for implementing the software resources.

Citing Bressoux, Sall (1997) shows that reducing the gap between strong and weak students depend on teachers. These would be divided in two main categories:

- Those that advance the average student outcomes: either by reducing the gap that existed originally between strong and weak, on the contrary, in accentuating;

- Those that do not advance the average student performance: while increasing the gap between the strong and the weak, or decreasing it.

However, educational equity should also be evaluated on several levels:

- Within the same class,

- In the same school for classes of the same level,

- In a city, a region or a country, for classes of the same level using the same programs.

We must remember that in our study, we measure the impact in terms of efficiency and equity of educational practices differentiated (teaching situations and situations of 
integration,teaching and integration situation combined) on student achievement. The results we have reached show that almost all students improve their average scores, but also that the gap between weak and strong students decreased substantially at the three post tests "resource" and "situation" compared to the pre-test, especially the group of classes "downstream" (those who practiced the situations of integration).

\subsection{Equity and efficacy in the educational practices}

As noted Opdenakker and Van Damme (2009), research on effective teaching can not be reduced to the identification of effective teaching practices or devices, because the panorama of variables or parameters to be investigated is effective much wider. Other variables such as "class-effect " or "school-effect" may also determine student performance.

According to Dumay and Dupriez (2009), one can observe that the performance of students in school systems vary based learning environments that represent the class or school to which they are enrolled. The authors claim that the anchoring of research on educational effectiveness is different from the anchor of the early research on the effectiveness of teaching methods and practices. Indeed, the ecological approach is now because the primary goal is to understand and explain variations in student performance according to their learning environment.

The question posed by authors in connection with the consideration of the effects of other predictors of effectiveness in education is what remains as part of variance explained by the teaching practices, once removed shares variance explained by the individual characteristics and the effects of class composition and institutions. Some research (not experimental) show that the impact of teaching practices seems disproportionately low and could discourage members of the school community.

The problem that could explain this phenomenon is based on the same methodological authors. Indeed, most current empirical research failed to measure validly teaching practices. The measures taken are declared or practices perceived practices and not necessarily actual practices because they are derived from responses given by the students and their teachers to the same questionnaires. It is therefore likely that the effects generated are more accountable to the representations that teachers teaching practices and their actual practices.

Following these reflections on the problem of measuring the effectiveness of explanatory variables (we dare say equity) teaching practices, our empirical research is experimental, in the sense that we "manipulated" pedagogical devices experimental groups and compared to those of the control group. Teaching practices in the experimental groups are not teaching practices reported but practical induced by experimenters: teachers were trained to implement learning focused on complex situations in science education (six days of training partitioned teachers, three months of practical complex situations under the supervision of the researcher, six tests carried out at regular and irregular intervals of apprenticeship).

Another aspect of the experimental manipulation is the fact that teaching practices were evaluated on basis of tests (pre-test and post-test) designed by the researcher himself and not by teachers. Administering examinations and corrections were made in limited and controlled conditions (same day and same start and end of the tests, collecting and marking scripts of 
students conducted with rigor).

According Dumay and Dupriez (2009), three variables are important to measure the effect of teaching practices, namely "the opportunity of learning", that is to say, the fact of whether the items contained in the tests were actually taught; "time on task" or the actual learning time; and the "structuring of learning", that is to say, learning that can be decomposed into a defined set of subtasks that lead to good results.

If we first consider the first variable on the appropriateness of learning, we believe having controlled in our empirical research because the items contained in the tests were the subject of training in prior to learning tests. Teachers sent us each time "exercises" they had conceived in terms of "situations" and "resources." It is based on these "exercises" then we were designing tests to measure the effect of different teaching practices.

Then the second variable on the real-time of learning "time on task" is difficult to measure, according to Dumay and Dupriez (2009), because at the same time apparent teaching (the same for all students) is the actual time that is very different for different students. Also it seems to be more the relationship between real-time $\mathrm{X}$ student learning and the apparent teaching time is the most relevant variable because some students better than others use the time to education offered by these authors. They also say that much of the learning time can be outside of instructional time.

As for the third variable that refers to the structuring of learning Dupriez Dumay (2009) argues that it can take different forms, the degree of relevance and effectiveness can vary from one object to learning, a kind of student to another and according to the profile of the teacher.

Regarding our research, we can recall that the purpose of learning offered is the same for all classes of our sample. The socio-economic conditions of the students are not the same (low income and low instruction for parents of students in the public network, relatively high income and high education for parents of students in private schools). Each teacher is naturally curious; but our teachers share certain characteristics with the level and field of qualification (3 years of general secondary education and three years of teaching and teaching practice). They also have over 5 years of professional experience.

The homogeneity of students in classes, coupled with the diversity of students in class groups (private or public schools) highlight the effectiveness or fairness of differentiated instructional practices. As we will see in the next section, results in the tests discriminate against groups of classes based on the types of teaching practices introduced. We see for example that the group practiced "situations downstream" has made significant progress in terms of both efficiency and equity.

\section{Methodology, procedures and results of the research}

The research concerned a sample of 38 classes of the fourth year of primary school (10 years old) from 20 schools in the district of Huye (Southern Rwanda). It aims to analyze the impact of each complex situations use in terms of equity, measured by student achievement. Thirty 
eight classes (about 1500 students) are representative of the public school population as well as that of the private schools. Before this research, none of the participating teachers used complex situations. The classes were divided into 4 groups, according to whether they developed the practice of teaching situations and / or situations of integration, as illustrated in the following table.

Table 1. Differentiated Practices of "Complex Situations"

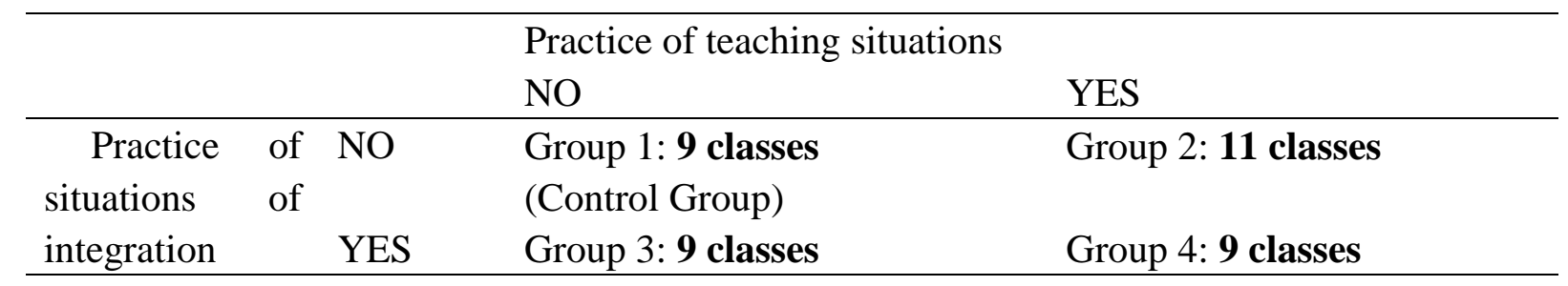

Before launching the research, none of the participating classes practiced either teaching situations or integration situations. Meanwhile, the researcher was neither a specialist in teaching situations nor in integration situations. We are therefore, in a relatively neutral about the past of the researcher (who is also the trainer of teachers) about the past and experimental classes.

Teachers received a three (3) day training on teaching situations (groups 2 and 4), and a three (3) day training on integration situations (groups 3 and 4). These trainings were conducted by the researcher. Training focused on the same content in all classes for the four groups: hand tools and their maintenance, water and environment, health.

To ensure that the initial level in the four groups is equivalent, two pre-tests were administered to students in 38 classes, before starting the experiment:

- One "resources" test on knowledge and know-how

- One "complex situations" test on the use of these complex situations.

In addition to the pre-test, three other tests were conducted to measure learning of resources and complex situations: one after 4 weeks of learning (post-test 1, week 5), another after 9 weeks of learning (post-test 2, week 10), and the third after 8 months of learning (post-test 3 ).

The following is an example of a complex situation test:

Level:Primary 4

Date:January, $27^{\text {th }} 2012$

Lesson: Science and elementary technology

Topic I: Hand tools and their maintenance

Competence: By the end of this topic the learner will be able to: 


\section{Macrothink}

-Use and maintain simple agriculture, carpentry and masonry hand tools.

\section{Pre-test}

\section{Situation: school desks}

The principal of our school wants to produce new pupil's desks by using the forest big trees near the school. But he doesn't know the tools to use and how to maintain them.

Task: advise the principal in order to find a) tools that he will use to make desks from trees.

b) tools that he will use to plant other trees.

\section{To the attention of pupils:}

-to read with attention the situation

-to answer by simple words

-to respect quiz time

-to make a clean copy
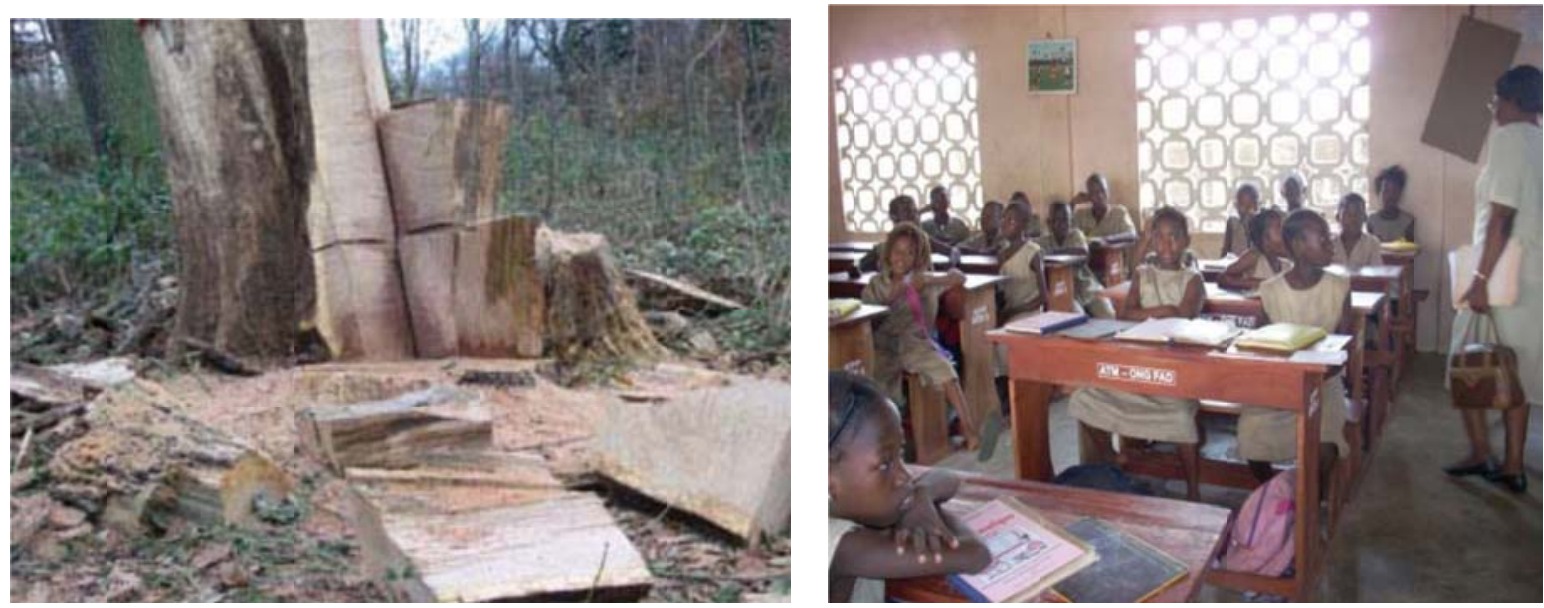

Figure 1. Situation support document

This one is an example of a "resource" test:

Level: Primary 4

Date:January, $27^{\text {th }} 2012$

Lesson: Science and elementary technology

Topic I: Hand tools and their maintenance

Competence: By the end of this topic the learner will be able to:

-Use and maintain simple agriculture, carpentry and masonry hand tools.

Pre-test

Resources 
Question

Identify a) 2 tools of a farmer

b) 1 tool of a carpenter

c) 2 tools of a manson

\section{Tothe attention of pupils:}

-to read with attention the questions

-to answer by simple words

-to respect quiz time: 40 minutes

-to make a clean copy

\subsection{Treatment of results in terms of equity}

As seen above, equity reform questions the differential benefits obtained from students, schools, teachers: the less favored initially did they get benefits at least equivalent to those of the most favored, if not higher? The difference between the two was it filled, or has it grown? According to Sall \& De Ketele (1997) and Solaux (2005), efficiency and equity are concepts that, increasingly, are regarded as inseparable in education. They argue that in fact the best way to increase the effectiveness of school systems is to increase the performance of all students, particularly those in less developed countries, and therefore increase equity.

The processing procedure is different from that followed during the treatment in relation to the efficiency. What interests us is the group level of students: the "strong" and "weak". These qualifiers are worthy of discussion. Roegiers (2004) distinguishes between false strong and true strong.

False strong or apparent strengths are students who have a mastery of the knowledge, know-how, the largest automated procedures. It is one that has sufficiently integrated the school system, to anticipate the types of questions that will be asked in evaluating student. The phenomenon of cramming, which is to lead to similar tests to those submitted to the student, in the hope of finding a proportion of identical questions or near the day of the exam, illustrates this phenomenon of false strong. The author claims that their achievements are often superficial and short term, and they are not able to use these assets, especially in a non-formal setting.

True strong are the reverse, according to the same author, competent students are, those who do not need to resort to tricks like cramming. What they learned, they learned well and can return it in matters of restitution, or use it in matters of implementation know-how. But mostly they draw their strength from the ability to transfer their acquired spontaneously. What they earned in a situation A, they are suitable enough to use it in a situation B.

The author also distinguishes the false weak and the true weak. False weak for him are those who fail because they are not scholarly, they do not fall within the operation of the school. 


\section{$\triangle$ Macrothink}

International Journal of Education

ISSN 1948-5476

2015, Vol. 7, No. 4

They do not lack resources, but how to measure does not reveal their strengths. The author claims that they are misunderstood by the system because they are competent, but their jurisdiction is not recognized.

Weak students fall into two categories. The first are those who have insufficient knowledge of the resources (knowledge, know-how, automated procedures). The others are those who, once they have acquired the resources are not able to integrate their acquired spontaneously. These are not able to transfer their acquired knowledge from a situation A to a situation B. They need special training to manage complexity, that is to say, learning to be able to solve complex situations in which must use their knowledge and skills they have learned. The first, those who do not know the resources, or some resources "keys" have probably also need to learn to manage this complexity, but they first need to master the necessary resources to solve complex tasks.

Regarding the extent of educational equity, purpose of this research, we identified students who have earned points in the trials 'situation' and those who have not progressed in each category of classes that have practiced different pedagogical approaches (teaching situations, situations of integration, teaching situation and situations of integration, and the control group). We considered the average gross earnings from the score at pre-test (test done before focuses on complex situations learning). We then calculated the students' progress based on the scores achieved in the post-tests (tests carried out during and after the introduction of new teaching practices). The procedures of treatment of these data are detailed below.

\subsection{Actual treatment}

We must remember that for the measurement of equity, we considered individual raw scores and not the middle class as we did for measuring teaching effectiveness of innovations. The reason is none other than equity, it is to measure the gains of students (individuals) weak or strong who start belonging to a set of classes that have practiced this or that approach to teaching.

We first set up a database of 1,194 scores (33 classes), then we imported the database initially addressed on Excel pages into SPSS (Statistical Package for the Social Sciences) software. A class belonging to the "control" group with the score at pretest of almost 9 out of 10 was removed because its scores are considered outliers. It means that we remain with 32 classes.

The first step was to clean the file by deleting all students who missed one (or more) of the 8 tests made during the empirical period because empty spaces are interpreted by the software as zero. This could distort our results. After this operation, 1,004 remained full scores.

Second, given that there has been a lot of zero rating at pretest, we have added to all notes of a pre-test score ( +1 ) except score 10 and we divided by 1.25 to balance all of that test scores pretest.

The third operation was to distinguish each category of weak students and strong students on the score to the "situation" pretest.

Note that the categorization of "weak" groups and "strong" was performed on all data (global 
data base) to treat in the same way the scores of all students. The first half of all scores is considered as low and the second one as strong. The figure below shows the results of the study in terms of equity.

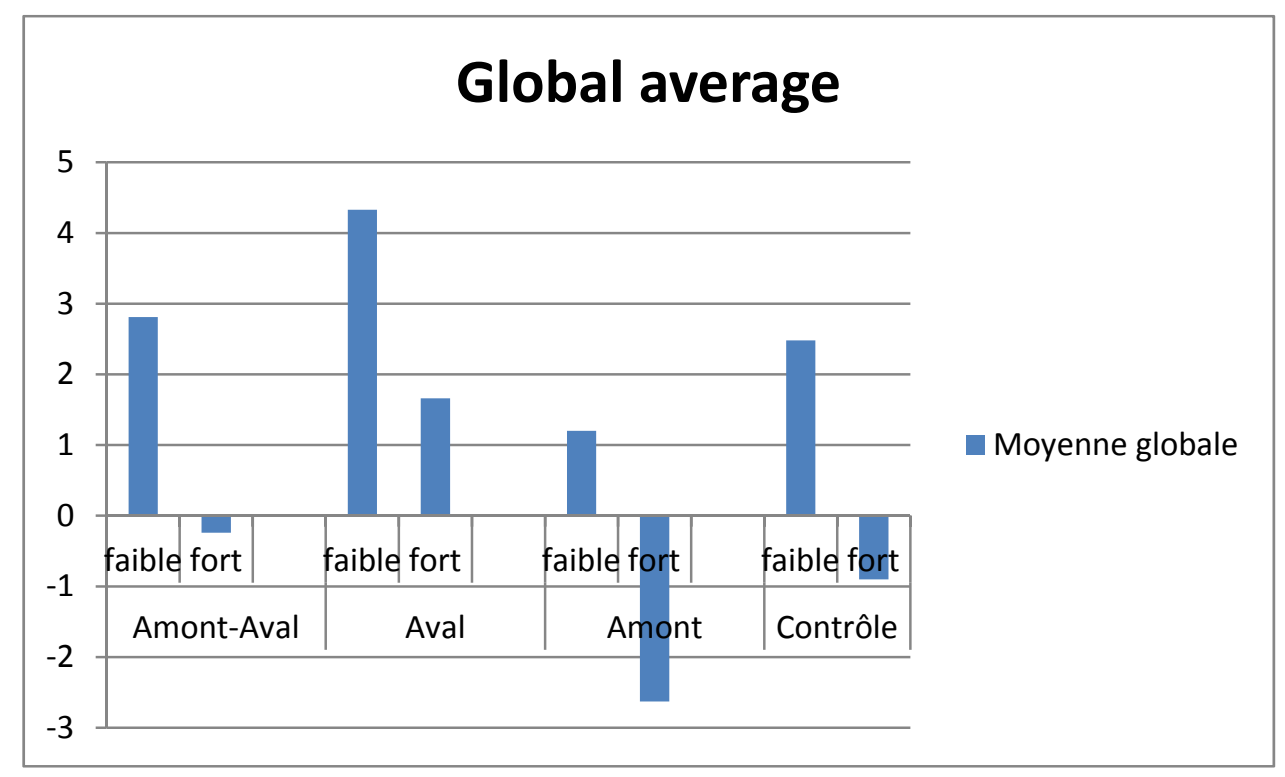

Figure 2. Summary of overall average earnings by level

\subsection{Discussion of Results}

If we start with the control group, which has not introduced as educational innovation, there is a large number of strong students who start to systematically and progressively to regress. Although the pre-test group has the highest number of "strong" students who did better, the effect of not learning to solve complex situations is revealed through the regression results to post-tests 1 and 2. If the group of "strong" has progressed relatively in the posttest 3, it does not exceed the average of the scores on the pre-test as above.

What we can say for weak students who have progressed to post-tests as they have not been trained to solve complex situations is that these are students who are capable of transferring their knowlege spontaneously without training. But these students are relatively few.

In the case for our research, teachers 'teaching situation' group (and those of the "situations of integration" group for that matter) were trained for three days, and had to introduce these changes over a period of 3 months. It is therefore understandable that the effect of teaching situations on student achievement could not be optimal in terms of equity.

The group "teaching situation + situations of integration" which is the one that simultaneously brings both innovations namely teaching situations and situations of integration. We have already seen that if one begins by introducing situations for learning resources, the problem of membership of teachers arises because the approach requires a radical change of habits of their teaching practices and a fairly extensive training. Since teachers are invited to practice situations and more integration, the task seems difficult. Reading the results of this group 
shows that in general students have gained 2.57 out of 10 (the average of the sum of the average earnings of strong and weak). But about fairness, only students who left a low score (92 weak students) gained 2.81 on strong students. That is to say, those who scored relatively high lost 0.24 out of 10 cannot be blamed for this decline as the twin requirements of this methodological approach.

In fact, some teachers have practiced only one approach, others have tried to do them simultaneously have not done systematically and effectively.

Finally, the "situations of integration" is the group that practiced situations downstream of learng. Indeed, the results of this group are so clear that one cannot attribute the effect that the approach is in question. Weak students earn 4.33 out of 10, which seems to be indicative of the impact of this approach on the performance of students initially more or less weak. Students called "strong" also earned 1.66 out of 10! It is interesting to note that this is the group that advanced the most weak and regress is less strong. It should also be noted that this group continues to advance low even at posttest 3 occurred 6 months after the post-test 2 Work individual integration permanently fixed knowledge.

As we have explained above, it seems that we cannot attribute these undeniable effects on student achievement at this educational device (situations of integration) that puteach student at the center of learning and offering him an opportunity to integrate the resources learned through complex situations. Overall, if we consider all groups, we can say that focusing on complex situations reduces the learning gap between strong and weak students because these students progress to an average of 2.78 points out of 10 while the first regress slightly 0.43 points out of 10 .

Taking into account some methodological limitations that on the one hand, in the case of this research, teacher training lasted six days, three for those who introduced complex situations teaching situations, three for those who have practiced the situations of integration. Those that combined both educational approaches participated in both sessions; while the device requires a relatively long for teachers to change their practices and that the children get used to this new way of working time; and secondly the fact that the trainer himself was not a specialist in complex situations. If these limits have not been able to neutralize the (positive) impact of the practice complex situations on student performance in terms of equity, it seems indisputable that these are the result of the effect of practice complex situations in their different ways.

In general, the comparative results confirm, both in terms of efficiency and in terms of equity, the main trends in countries that practice a similar approach, notably in Mauritania, Djibouti and Madagascar trends. In these countries, studies show that in terms of efficiency, the implementation of integration modules offering a systematic work on complex situations can save 1 to 1.5 points out of 10 in tests "complex situations". In terms of equity, is observed in the same countries that have generalized the pedagogy of integration significantly greater gain for less advanced students for more advanced students (Roegiers, 2010).

In terms of equity (our research), practice complex situations benefit all students, especially the weakest in trials "situations" with an overall average gain of 2.78 experimental groups of 10 , 
slightly more than $27 \%$ overall. But if we consider the "downstream situations" or situations of integration approach, it is easy to see that it advances the weak students from an average of 4.33 points out of 10 (over 40\%) . These results are extremely significant when compared to others from similar research.

Thus, if the results of this study comprehensively analyzed in terms of equity, it is necessary to highlight three main findings:

(1) reducing the gaps between the scores of low achievers and those of strong students is clearly linked with dealing with situations of integration, that is to say the practice is the integration of acquired;

(2) in all groups, there is an "equalization" that occurs between the notes of the weak and strong: this equalization is a "race to the bottom", as in "upstream or teaching situations" group or a race up, as in the "downstream or situations of integration" group and to a lesser extent in the "upstream-downstream (two)" group;

(3) there is an overall consistency of results, if the results of the "upstream-downstream" group is examined, we find that, for both weak and for strong, they are so nearly perfect, the average of those of the "upstream" group and those in the "downstream" group (2.81 is almost the average between 4.33 and 1.20 (2.76) -0.24 is close to the average between 1.66 and - 2.63 $(-0.32)$., we regard this as an a posteriori validation of all results, and our methodological device.

About the test results "resources" analyzed for fairness, we did not want to present them because they do not discriminate against different approaches "complex situations." The control group behaves the same way as other groups in terms of the gains of weak groups and strong groups. We believe that the competence of a student is measured against its ability to resolve complex situations, this is why the tests "complex situations" better discriminate pedagogical approaches used by teachers that the tests "resources." That's why we did not consider it appropriate to present these results in this dissertation.

\section{Conclusion}

It appears from the analysis of these results that the practice of complex situations in science education is changing learners like wildfire in both races "situations" in the trials 'resources' in terms of efficiency than equity. These results confirm, with more clarity and evidence, other studies conducted in other developing countries such as Rwanda, namely Djibouti, Mauritania, Madagascar (Roegiers, 2010).

Results of the study shows that the "teaching situations" is the group that practiced complex situations for learning resources. If the results that you consider, you realize that on the one hand, this is the group that has the largest number of students in low and start with the least wins. Furthermore, this group has the smallest number of students in strong start and earned the least (or most lost). This would mean that overall it is a group that has not (almost) benefited from the exploitation of complex situations problems. Obviously, weaker still have a little progress.

The reason is both the order of the accession of the teachers and the effort required for their 
initial training (Roegiers, 2010). Indeed, the practice of driving situations in advance (as we said above) requires for teachers a deep change of habits and daily teaching practices. Therefore, Roegiers (2010) argues that in Western countries, despite the major training effort made, a significant proportion of teachers cannot naturally enter into this type of approach that is based on participatory methods on interdisciplinarity, learning by problem solving.

The author also states that this change in practice usually takes a long time to settle permanently. It is generally believed that it takes 5 to 10 years for teachers to spontaneously adopt problem-based learning instead of transmissive practices.Then, the first research question "How and to what extent the introduction of teaching situations have an impact on student's results in learning SET in terms of equity?” is answered.

The second research question "How and to what extent the introduction of integration situations influence student's results in learning SET in terms of equity?" finds it's answer through the fact that analyses show more specifically that the practice of situations of integration stand out from the other two types of practices due to the relatively higher earnings it saves learners equity. This is due to the fact that it motivates: it helps give meaning to learning; it is rewarding: it gives students feeling valued for what they can accomplish through the challenges of complex situations; it is progressive and inclusive: while creating a break in the approach to learning, it is a continuation of existing practices; it is open: it has a high potential for contextualisation of learning (Roegiers, 2010, pp 166-167.).

In terms of equity, the results show that working with complex situations downstream/situations of integration reduces remarkably the differences between strong and weak students by increasing week student scores. The emphasis on individual work especially during phases of integration of acquired primarily benefits students who are not able to move spontaneously.

The remarkable gain of the downstream group/situations of integration is also linked to the methodological simplicity of the practice of complex situations of integration. Indeed, with respect to this model, the teacher is asked to change its practices in two stages. Initially, the teacher is free to conduct learning resources according to its usual practice, without having to practice learning situations resources. Then the teacher has students at a steady pace, complex situations in which they use the acquired resources to resolve these situations. Secondly, teachers are invited to change their practices in terms of daily use pedagogies of learning including at their own pace, and according to that teaching style that suits him.

Finally, the third practice related to the one which simultaneously brings both innovations "teaching situations and situations of integration" do not reduce the difference between strong and weak students by making a small progress of weak student's score. The reason seems to be difficulties encountered by teachers to practice simultaneously two innovations. This is to answer the third research question related to: "How and to what extent introducing the two approaches simultaneously, impact on student's results in terms of equity"

The teaching of science which applies the practice of complex situations in this research particularly requires an investigative approach that develops curiosity, creativity, critical 
thinking and interest in the learner. The complex situations and educational purpose complex integrative function situations are valuable devices when they are put in the center of the investigative approach in science education.

\section{References}

Aden, H.M., \& Roegiers, X. (2003). A quels élèves profite l'approche par les compétences debase? Etude de cas à Djibouti.

Amin, M.E. (2004). The Evaluation of the Pilot Experiment on the Reduction of ClassRepetition in Cameroon Primary Schools. MINEDUC/ADB: Yaoundé.

Belgian Technical Cooperation (1996). Support to basic education. Retrieved from: http://www.btcctb.org/doc/UPL-2007010517525320946.pdf

De Ketele, J-M., \& Postic, M. (1988). Observer les situations éducatives. Paris: PUF

Dumay, X., \& Dupriez, V. (2009). L'efficacité dans l'enseignement. Promesses et zonesd'ombre. Bruxelles: De Boeck.

Legendre, M-F. (1994). Problématique de l'apprentissage et de l'enseignement des sciencesau secondaire: un état de la question. Revue des sciences de l'éducation, 20(4), 657-677. http://dx.doi.org/10.7202/031761ar

Ministry of Education (2010). Science and Elementary Technology. Curriculum for upperprimary, Kigali.

Ministry of planning and finance (2002). Rwanda 2020 vision, Kigali.

OECD (2012). Equity and Quality in Education: Supporting Disadvantaged Students and Schools. http://dx.doi.org/10.1787/9789264130852-en

Peyser, A., Gerard, F.-M., \& Roegiers, X. (2006). Implementation of a pedagogy of integration: some thoughts based on a text book elaboration experience in Vietnam. Planning andchanging, 37(1 \& 2), 37-55.

Roegiers, x. (2001). Une pédagogie de l’intégration. Compétences et intégration des acquisdans l'enseignement. Bruxelles, De Boeck Université.

Roegiers, x. (2003). Des situations pour intégrer les acquis scolaires. Bruxelles, De Boeck Université.

Roegiers, X. (2010). Pedagogy of integration.Education and training systems at the heart ofour societies. Brussels, ed. De Boeck University.

Roegiers, X. (2011). Curricula et apprentissages au primaire et au secondaire. La pédagogiede l'intégration comme cadre de réflexion et d'action. Bruxelles: De Boeck.

Savin-Badeu, M., \& Major, C.H. (2004). Foundations of problem-based learning. Buckingam: S.R.H.E, Open University press. 
Unesco (2010). World data of education. Retrieved from http://www.ibe.unesco.org/fileadmin/user_upload/Publications/WDE/2010/pdf-versions/ Cameroon.pdf

\section{Copyright Disclaimer}

Copyright for this article is retained by the author(s), with first publication rights granted to the journal.

This is an open-access article distributed under the terms and conditions of the Creative Commons Attribution license (http://creativecommons.org/licenses/by/3.0/). 